\title{
Obstructed solitary ectopic pelvic kidney
}

\author{
Chia-Ter Chao
}

Received: 30 June 2012/ Accepted: 5 August 2012/Published online: 22 August 2012

(C) Japanese Society of Nephrology 2012

Keywords Chronic renal insufficiency .

Congenital abnormality $\cdot$ Renal ectopia

A 72-year-old lady presented for abnormal renal function evaluation. She had a history of diabetes mellitus and hypertension, controlled with indapamide and insulin. Physical examination revealed a normotensive female without leg edema. Laboratory study showed abnormal renal function (creatinine $2.15 \mathrm{mg} / \mathrm{dL}$ ) and $1+$ proteinuria without hematuria. Renal sonography disclosed absence of both kidneys over native sites. Abdominal computed tomography identified her kidney being situated inside the pelvic cavity behind the pubic symphysis, with a blood supply from the right common iliac artery (Fig. 1, left). Mildly dilated proximal ureter was also noted (Fig. 1, right). She refused retrograde pyelography or nephrostomy owing to the inherent risk, and continued to receive follow-up without renal function deterioration.

Congenital urologic anomalies estimatedly occur in $10 \%$ of all births, but pelvic ectopic kidney is rare (incidence 1/3000) [1]. Chronic obstruction or nephrolithiasis is common in these patients [2], and can potentially be a cause of chronic kidney disease, as in our patient.

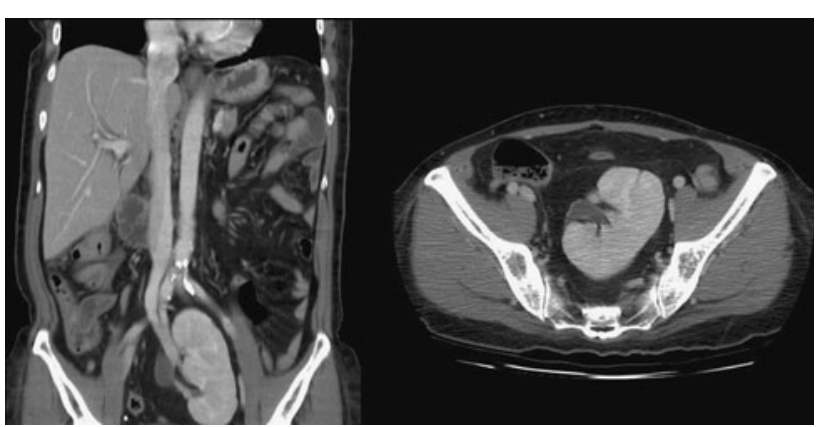

Fig. 1 Left (coronary view) solitary ectopic kidney was noted in pelvic cavity. Renal fossa was empty bilaterally. Right (axial view) mildly dilated proximal ureter was noted

Conflict of interest The author declares that he has no competing interest.

\section{References}

1. Cinman NM, Okeke Z, Smith AD. Pelvic kidney: associated diseases and treatment. J Endourol. 2007;21:836-42.

2. Lu CC, Tain YL, Yeung KW, Tiao MM. Ectopic pelvic kidney with urinary tract infection presenting as lower abdominal pain in a child. Pediatr Neonatol. 2011;52:117-20.
C.-T. Chao $(\bowtie)$

Department of Traumatology, National Taiwan University

Hospital, No. 7, Chung-Shan South Road,

10100 Taipei, Taiwan

e-mail: ctchao@ntuh.gov.tw 